\title{
Sophorolipids Production by Candida bombicola ATCC 22214 and its Potential Application in Microbial Enhanced Oil Recovery
}

\author{
Abdulkadir E. Elshafie', Sanket J. Joshi1,2, Yahya M. Al-Wahaibi', Ali S. Al-Bemani' \\ Saif N. Al-Bahry ${ }^{1 *}$, Dua'a Al-Maqbali' and Ibrahim M. Banat ${ }^{4}$
}

'Department of Biology, College of Science, Sultan Qaboos University, Muscat, Oman, ${ }^{2}$ Central Analytical and Applied Research Unit, College of Science, Sultan Qaboos University, Muscat, Oman, ${ }^{3}$ Department of Petroleum and Chemical Engineering, College of Engineering, Sultan Qaboos University, Muscat, Oman, ${ }^{4}$ School of Biomedical Sciences, University of Ulster, Coleraine, UK

\section{OPEN ACCESS}

Edited by:

Wael Ahmed Ismail,

Arabian Gulf University, Bahrain

Reviewed by:

Christopher Joseph Ennis,

Teesside University, UK Kamaljeet K. Sekhon Randhawa, Aalborg University Copenhagen,

Denmark

*Correspondence:

Saif N. Al-Bahry

snbahry@squ.edu.om

Specialty section:

This article was submitted to Microbiotechnology, Ecotoxicology and Bioremediation,

a section of the journal

Frontiers in Microbiology

Received: 08 June 2015 Accepted: 10 November 2015 Published: 26 November 2015

Citation:

Elshafie AE, Joshi SJ, Al-Wahaibi YM Al-Bemani AS, Al-Bahry SN, Al-Maqbali D and Banat IM (2015) Sophorolipids Production by Candida bombicola ATCC 22214 and its Potential Application in Microbial

Enhanced Oil Recovery.

Front. Microbiol. 6:1324. doi: 10.3389/fmicb.2015.01324
Biosurfactant production using Candida bombicola ATCC 22214, its characterization and potential applications in enhancing oil recovery were studied at laboratory scale. The seed media and the production media were standardized for optimal growth and biosurfactant production. The production media were tested with different carbon sources: glucose $(2 \% \mathrm{w} / \mathrm{v})$ and corn oil $(10 \% \mathrm{v} / \mathrm{v})$ added separately or concurrently. The samples were collected at $24 \mathrm{~h}$ interval up to $120 \mathrm{~h}$ and checked for growth $\left(\mathrm{OD}_{660}\right)$, and biosurfactant production [surface tension (ST) and interfacial tension (IFT)]. The medium with both glucose and corn oil gave better biosurfactant production and reduced both ST and IFT to $28.56 \pm 0.42 \mathrm{mN} / \mathrm{m}$ and $2.13 \pm 0.09 \mathrm{mN} / \mathrm{m}$, respectively within $72 \mathrm{~h}$. The produced biosurfactant was quite stable at 13-15\% salinity, $\mathrm{pH}$ range of $2-12$, and at temperature up to $100^{\circ} \mathrm{C}$. It also produced stable emulsions ( $\% \mathrm{E}_{24}$ ) with different hydrocarbons (pentane, hexane, heptane, tridecane, tetradecane, hexadecane, 1-methylnaphthalene, 2,2,4,4,6,8-heptamethylnonane, light and heavy crude oil). The produced biosurfactant was extracted using ethyl acetate and characterized as a mixture of sophorolipids (SPLS). The potential of SPLs in enhancing oil recovery was tested using core-flooding experiments under reservoir conditions, where additional $27.27 \%$ of residual oil $\left(S_{o r}\right)$ was recovered. This confirmed the potential of SPLs for applications in microbial enhanced oil recovery.

Keywords: biosurfactant, sophorolipids, Candida bombicola, microbial enhanced oil recovery, core-flood experiment

\section{INTRODUCTION}

Surfactants are amphiphilic molecules consisting of both hydrophilic and hydrophobic domains that partition preferentially at the interface between fluid phase with different degree of polarity and hydrogen bonding (such as oil and water or air and water). Surfactants intercede in nearly every product and aspect of day to day life, with a total world production exceeding 13 million tons per year (Levison, 2009). Nearly half is used in household and laundry detergents and inevitably ends up in the environment after use, which results in a negative impact on aquatic system since 
traditional surfactants have low rate of biodegradation, highecotoxication and bio-accumulation (Mann and Boddy, 2000; Mann and Bidwell, 2001). Biosurfactants in comparison are a heterogeneous group of surface active molecules synthesized by microorganisms which reduces surface tension (ST) and interfacial tension (IFT) and plays a vital role in microbiological physiology (Al-Sulaimani et al., 2011a). Biosurfactants can be produced from renewable feedstock or even agro-industrial waste products (Joshi et al., 2008; Van Bogaert et al., 2011; Al-Bahry et al., 2013). Biosurfactants have advantages over chemical surfactants, because of their lower toxicity, higher biodegradability, better environmental compatibility and higher selectivity and specific activity at extreme temperature, $\mathrm{pH}$ and salinity (Marchant and Banat, 2012a). Biosurfactants have been applied in many fields including the oil industry, both for petroleum production and for incorporation into oil formulations which are considered as the largest possible market (Marchant and Banat, 2012b). Other application related to the oil industries includes oil spill bioremediation/dispersion, both inland and at sea, bioremediation of non-aqueous phase liquids (NAPL), removal/mobilization of oil sludge from storage tanks and to enhance oil recovery (Banat et al., 1991; Sen, 2008; Joshi and Desai, 2010). The second largest market for biosurfactants are emulsion polymerization for paints, paper coating and industrial coatings.

Major classes of biosurfactants are glycolipids, lipopeptides, lipoproteins, phospholipids, fatty acids, polymeric surfactants and particulate surfactants (Desai and Banat, 1997). Glycolipidic biosurfactants are extracellular surface active molecules produced by many microorganisms, e.g., sophorolipids (SPLs) produced by yeast - Candida bombicola (formerly called Torulopsis bombicola). C. bombicola was isolated from bumblebee honey (Kachholz and Schlingmann, 1987). SPLs are amongst one of the most promising biosurfactants. They are produced by nonpathogenic yeast strains; in contrast to rhamnolipids which represent another commercially available glycolipid surfactant that is available industrially, but produced by the opportunistic pathogenic bacteria Pseudomonas aeruginosa (Van Bogaert et al., 2007). Generally SPLs are produced as a mixture of slightly different molecules with variations in acetylation and lactonisation. In general, lactonic SPLs are reported to be having better ST lowering and antimicrobial activity, whereas the acidic SPLs are generally better foaming and solubility agents. Furthermore, the acetyl groups render the molecule less water soluble, but enhance their anti-viral and cytokine stimulating effects (Shah et al., 2005). Van Bogaert et al. (2007) reported the production and applications of SPLs produced by various yeast strains.

In this paper we investigated the effect of carbohydrate and oil based media on biosurfactant production by $C$. bombicola ATCC 22214. The biosurfactant was extracted and characterized using high-performance thin layer chromatography - mass spectrometry (HPTLC-MS), matrix-assisted laser desorption ionization - time of flight-mass spectroscopy (MALDI-TOFMS) and nuclear magnetic resonance (NMR) spectroscopy $\left({ }^{1} \mathrm{H}\right.$ and $\left.{ }^{13} \mathrm{C} \mathrm{NMR}\right)$. The stability of the biosurfactant under extreme conditions of $\mathrm{pH}$, temperature and salinity was also investigated and finally we tested its efficacy in enhancing oil recovery using core-flood experiments.

\section{MATERIALS AND METHODS}

All of the experimental data were expressed in terms of arithmetic averages obtained from at least three independent replicates, with standard deviation $( \pm)$.

\section{Chemical and Reagents}

All chemicals and reagents used were of analytical grade, media constituents for microbial studies were of microbiology grade, and the hydrocarbons had minimum of $99 \%$ purity. All chemicals, reagents and hydrocarbons were purchased from Sigma-Aldrich Co. LLC. Corn oil was purchased from local market. Light and heavy crude oil were kindly provided by local oil company, Petroleum Development Oman (PDO).

\section{Microorganism and its Maintenance}

The yeast C. bombicola ATCC22214 was sub- cultured from the stock culture on freshly prepared potato dextrose agar slants (PDA), composition (g/l): potato extract, 4.0; dextrose, 20.0; agar, 15.0) and glucose yeast peptone agar slants (GYPA), composition (g/l): glucose, 100; yeast extract, 30; peptone, 50; agar, 20; and incubated at $\left(25^{\circ} \mathrm{C}\right)$ for $48 \mathrm{~h}$. The agar slants were preserved at $5^{\circ} \mathrm{C}$.

\section{Seed Culture Preparation}

Two types of seed media were used for developing the seed culture: potato dextrose broth (PDB) and glucose-yeast extracturea broth (GYUB), composition (g/l): glucose, 50; yeast extract, 5 ; urea, 0.5 . Seed media were prepared and distributed $50 \mathrm{ml}$ each in $250 \mathrm{ml}$ Erlenmeyer flasks and autoclaved at $121^{\circ} \mathrm{C}$ and $15 \mathrm{psi}$ for $15 \mathrm{~min}$. Seed media flasks were inoculated with a loop full of the microorganism freshly grown on GYPA or PDA agar slant, and incubated for $48 \mathrm{~h}$ at $25^{\circ} \mathrm{C} ; 160 \mathrm{rpm}$ in a rotary incubator shaker.

\section{Preparation of Production Media}

Three different production media were tested containing $(\mathrm{g} / \mathrm{l})$ : yeast extract, 10; urea, 1; and different carbon sources. The $\mathrm{pH}$ was adjusted to 4.0 using $1 \mathrm{M} \mathrm{HCl}$, before autoclaving. Glucose and/or corn oil was used as carbon sources, as: only glucose $(2 \%$ $\mathrm{w} / \mathrm{v})$, only corn oil $(10 \% \mathrm{v} / \mathrm{v})$ or both glucose $(2 \% \mathrm{w} / \mathrm{v})$ and corn oil $(10 \% \mathrm{v} / \mathrm{v})$. Glucose and corn oil were autoclaved separately and added to pre-sterilized production media. The flasks were inoculated with $2 \%(\mathrm{v} / \mathrm{v})$ pre-grown seed media (GYUB) and incubated in a rotary shaker at $25^{\circ} \mathrm{C}, 160 \mathrm{rpm}$ for $120 \mathrm{~h}$. Samples were withdrawn every $24 \mathrm{~h}$ for different analysis: growth $\left(\mathrm{OD}_{660}\right)$, $\mathrm{pH}, \mathrm{ST}$, and IFT.

\section{Surface Tension and Interfacial Tension Measurements}

A pendent drop tensiometer (DSA100, KRUSS, Germany) was used to measure ST and IFT. The IFT was measured against 
hexadecane as the embedding phase as reported by Al-Sulaimani et al. (2011b). All measurements were done in triplicate at ambient temperature $\left(25 \pm 2^{\circ} \mathrm{C}\right)$ and pressure $(1 \mathrm{~atm})$ and the average of three readings were reported for each of the three independent experiments.

\section{Stability Studies}

The stability of biosurfactant produced by C. bombicola was studied under various environmental parameters including wide range of temperature, $\mathrm{pH}$ and different salt $(\mathrm{NaCl})$ concentrations. The study was carried out by changing the levels of one parameter while keeping other parameters constant using cell-free biosurfactant broth centrifuged at $10,000 \times g$ for $15 \mathrm{~min}$. ST and IFT were measured after each treatment to test their effect on biosurfactant activity.

\section{Temperature Stability Tests}

For the temperature stability test, $25 \mathrm{ml}$ of the cell-free broth were added in $50 \mathrm{ml}$ glass tubes and tightly closed with stopper to prevent evaporation. The tubes were incubated at different temperatures $\left(40,60,80\right.$, and $\left.100^{\circ} \mathrm{C}\right)$ each for $30 \mathrm{~min}$, cooled down to room temperature and the biosurfactant activity was measured.

\section{Salinity Stability Tests}

Different concentrations of salt $(\mathrm{NaCl})$ were added $(1,3,5,7$, $10,13,15,20$, and $25 \% \mathrm{w} / \mathrm{v}$ ) into $25 \mathrm{ml}$ cell-free broth, dissolved completely and the effect on biosurfactant activity was measured.

\section{pH Stability Tests}

For the pH stability study, $25 \mathrm{ml}$ of cell-free broth was adjusted using either $1 \mathrm{~N} \mathrm{HCl}$ or $1 \mathrm{~N} \mathrm{NaOH}$ to desired values $(2,4,6,8,10$, and 12) and the effect on biosurfactant activity was measured.

\section{Emulsification Index $\left(\% \mathrm{E}_{24}\right)$}

The emulsification index $\left(\% \mathrm{E}_{24}\right)$ was analyzed using previously reported procedures (Al-Wahaibi et al., 2014; Ismail and Dadrasnia, 2015): two $\mathrm{ml}$ of the cell-free broth was added to an equal amount of different hydrocarbons ( $n$-hexadecane, heptane, hexane, $n$-tetradecane, 1-methylnaphthalene, $n$-pentane, $n$-tridecane, 2,2,4,4,6,8-heptamethylnonane, heavy crude oil and light crude oil). The solution was mixed by vortexing for 2-3 min at high speed and was left to stand for $24 \mathrm{~h}$. After $24 \mathrm{~h}$ the height of the emulsion was measured and the emulsification index was given as the percentage of the height of the emulsified layer divided by the total height of the liquid column multiplied by 100 .

\section{Extraction of Biosurfactant}

Biosurfactant was extracted and partially purified by solventextraction. The cells were removed by centrifugation $(10,000 \times g$, $15 \mathrm{~min}$ at $20^{\circ} \mathrm{C}$ ) to obtain cell-free broth. The cell-free broth (1L) was extracted twice with an equal volume of ethyl acetate, shaken vigorously in a separation funnel. The bottom aqueous layer and the top ethyl acetate layers were collected separately. The aqueous portion was re-extracted further twice with ethyl acetate. Ethyl acetate extracts were combined and the solvent was evaporated under vacuum using Rotavapor (Buchi, Switzerland) to give crude biosurfactant along with residual oil. The residual oil was removed by washing thrice with $n$-hexane. Crude biosurfactant was recovered by evaporating the $n$-hexane (Wadekar et al., 2012).

\section{Biosurfactant Characterization High-Performance Thin Layer Chromatography-Mass Spectroscopy}

Biosurfactant was separated and analyzed using an automated HPTLC system (CAMAG, Switzerland) in the Central Analytical and Applied Research Unit (CAARU), Sultan Qaboos University, Oman. Twenty five microliter samples were spotted onto a $10 \mathrm{~cm} \times 10 \mathrm{~cm}$ pre-coated silica gel HPTLC plate (Merck, Germany) containing green fluorescent $F_{254}$. These samples were spotted under a flow of nitrogen gas using automatic TLC sampler 4 (ATS 4) spotting device (CAMAG, Switzerland). The plates were developed using an automatic developing chamber ADC 2 (CAMAG, Switzerland) with remote operation from winCATS software, containing solvent systems MP1: Chloroform: Methanol: Acetic acid (95:5:5) and MP2: Chloroform: Methanol: Water (65:15:2). The documentation and evaluation of the TLC plate was done using TLC visualizer (CAMAG) under direct UV 254 and UV $366 \mathrm{~nm}$ light, capturing the images. The separated bands were extracted and eluted by TLC-MS interface (CAMAG, Switzerland), based on the coordinates determined by the TLC scanner 4 . The TLC-MS interface head (oval, $4 \times 2 \mathrm{~mm}$ ) was connected to the pump (11 PLUS, HARVARD APPARATUS, Holliston, MA, USA) and the extraction was performed at a flow rate of $10 \mu \mathrm{l} / \mathrm{min}$, with methanol: acetonitrile $(50 \%$ diluted with water) - 1:10. The interface outlet was directly connected with the ESI - MS (Qaattro UltimaTM Pt, Micromass ${ }^{\circledR}$, UK), using Mass Lynx V4.0 software. The experimental conditions were: capillary voltage, $3.0 \mathrm{kV}$; cone voltage, $35 \mathrm{~V}$; lens voltage, $0.0 \mathrm{~V}$; source block temperature, $100^{\circ} \mathrm{C}$; desolvation temperature, $120^{\circ} \mathrm{C}$; analyzed under both positive and negative modes.

\section{Matrix Assisted Laser Desorption Ionization -Time of Flight}

All MALDI-TOF experiments were performed at CAARU, Sultan Qaboos University, on UltraFlextreme (Bruker Daltonics, Bremen, Germany) operating in positive reflectron mode in the $\mathrm{m} / \mathrm{z}$ range of 50-2000 Da. Stainless steel MTP 384 target plate was used for all the molecular weight analysis. Dihydroxy benzoic acid (DHB) dried droplet protocol described in Bruker manual was employed for sample preparation and spotting. Two micro liter of 2, 5-DHB matrix $(20 \mathrm{mg} / \mathrm{ml})$ in TA 30 (30:70 v/v ACN:TFA 0.1\%TFA) was premixed with $2 \mu \mathrm{l}$ of the sample solution. One micro liter of the mixture was applied to the ground steel target plate, dried at room temperature. The spectra were acquired using FlexControl software v3.3 (Bruker Daltonics, Bremen, Germany). A SmartBeam-II laser, set at a frequency of $1000 \mathrm{~Hz}$, was used for ionization. The laser strength was optimized at 25-35\%. A summed spectrum was obtained for each MALDI-spot. Peaks were detected using 

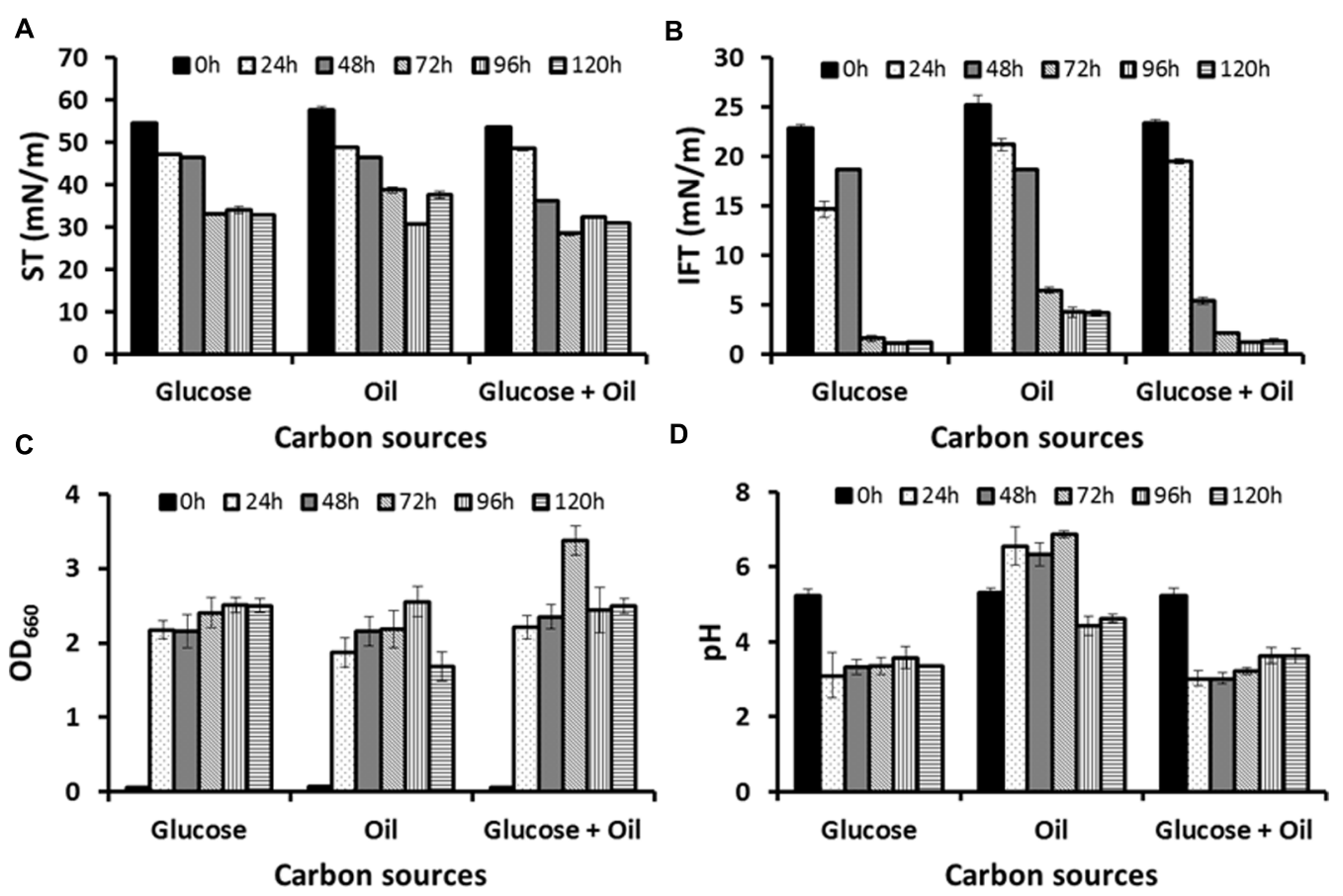

FIGURE 1 | Production profile for Candida bombicola ATCC 22214, when grown in medium with glucose, corn oil or both glucose and corn oil as a carbon source: (A) surface tension (ST), (B) interfacial tension (IFT), (C) Growth - OD 660 , and (D) pH profile.

the SNAP peak detection algorithm and a baseline subtraction was carried out using "TopHat" algorithm. The MALDITOF spectra were externally calibrated using a commercially available peptide mix (peptide calibration standard II, Part-No \#222570, Bruker Daltonics, Germany). FlexAnalysis Software v3.3 (Bruker Daltonics) was used for visualization and initial data processing.

\section{Nuclear Magnetic Resonance spectroscopy}

The NMR experiments were carried out in Bruker Avance III $\mathrm{HD} 700 \mathrm{MHz}$ spectrometer equipped with $5 \mathrm{~mm}$ TCI H/C/N cryoprobe. The proton $\left({ }^{1} \mathrm{H}\right)$ NMR experiment was run using zg30 pulse program operating at $176.08 \mathrm{MHz}$. Acquisition parameters were as follows: $90^{\circ}$ proton pulse width of $8.00 \mu \mathrm{s}$, relaxation delay of $1 \mathrm{~s}, 16$ scans. The proton decoupled ${ }^{13} \mathrm{C} \mathrm{NMR}$ experiments were carried out using composite pulse decoupling scheme operating at $176.08 \mathrm{MHz}$. Acquisition parameters were as follows: $90^{\circ}$ proton pulse width of $8.00 \mu \mathrm{s}$, relaxation delay of $2 \mathrm{~s}, 512$ scans. The Spectra were recorded in $\mathrm{CDCl}_{3}$ at $298 \mathrm{~K}$ and processed using TOPSPIN 3.2 software.

\section{Core-flooding Experiments}

Berea sandstone cores (1.5 inch diameter $\times 3$ inch long) were used for core-flooding experiments. The average porosity and permeability of Berea core-plugs were $20 \%$ and $250-350 \mathrm{mD}$ respectively. The formation water and crude oil used in these experiments were obtained from an Omani oil field of interest which has an average reservoir temperature of $60^{\circ} \mathrm{C}$. The salinity of the formation water was between 7 and $9 \%$ its chemical composition was $\left(\mathrm{kg} / \mathrm{m}^{3}\right)$ : Sodium, 25.083; Calcium, 3.762; Magnesium, 0.878; Iron, 0.045; Chloride, 47.722; Sulfate, 0.247; Bicarbonate, 0.079. Formation water was filtered prior to use, by Millipore Membrane Filtration Unit $(0.45 \mu \mathrm{m})$. The crude oil used for core-flood experiments was of API $36.51^{\circ}$. For all core-flooding experiments, cleaned Berea cores were saturated with filtered formation brine using vacuum desiccators for $24 \mathrm{~h}$ and pore volume (PV) was determined using the dry and wet weights of the cores. The cores were then flooded with crude oil at $24 \mathrm{~cm}^{3} / \mathrm{h}$ until no more water was produced. The oil initially in place (OIIP) was determined, which was indicated by the volume of water displaced. The cores were subjected to water-flooding at $24 \mathrm{~cm}^{3} / \mathrm{h}$ until no further oil was produced. The residual oil was calculated by measuring the amount of oil produced from the water-flood. Then, $5 \mathrm{PV}$ of the cell-free supernatant (biosurfactant broth) was injected as a tertiary recovery stage and extra oil recovery was determined (Al-Sulaimani et al., 2011b). All core-flood experiments were carried out at $60^{\circ} \mathrm{C}$ to mimic the average reservoir temperature of the field of interest.

\section{RESULTS AND DISCUSSION}

\section{Biosurfactant Production Studies}

Two different media GYUB and PDB were tested as seed media of which GYUB supported better growth (GYUB: $\mathrm{OD}_{660}=2.441 \pm 0.02$, and PDB: $\left.\mathrm{OD}_{660}=2.085 \pm 0.03\right)$ and hence selected as a seed medium for inoculum preparation. 


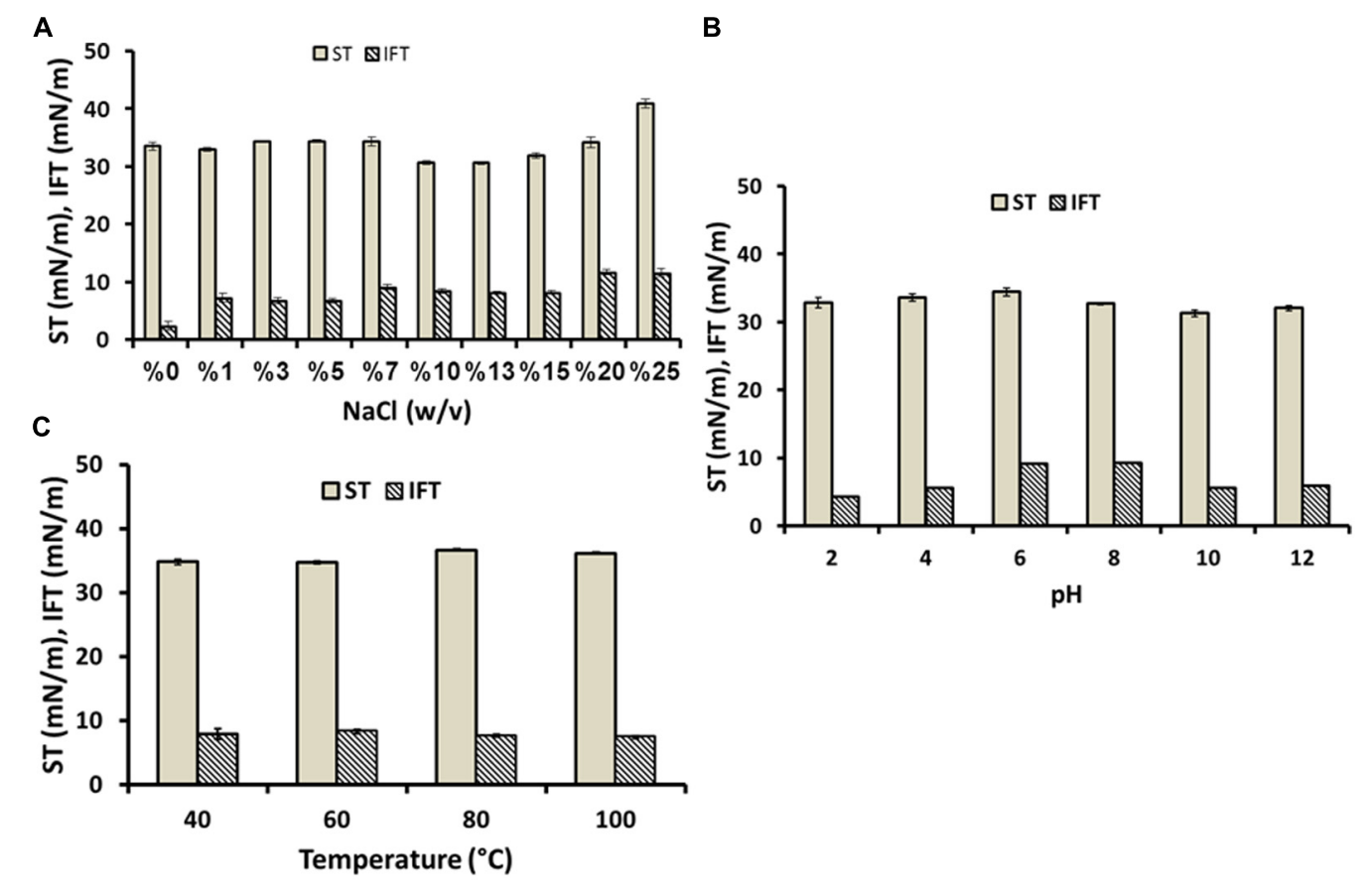

FIGURE 2 | Effect of salinity (A), pH (B), and temperatures (C) on the activity of biosurfactant produced by C. bombicola ATCC 22214.

To study the biosurfactant production, two different carbon sources (glucose and corn oil) were tested either alone or as a mixture of both. Growth $\left(\mathrm{OD}_{660}\right)$ and biosurfactant production (ST and IFT) were studied from all three different production media up to $120 \mathrm{~h}$. In glucose-based production medium both ST and IFT decreased after $72 \mathrm{~h}$, and reached to $33.08 \pm 0.05 \mathrm{mN} / \mathrm{m}$ and $1.63 \pm 0.29 \mathrm{mN} / \mathrm{m}$ from $54.66 \pm 0.26 \mathrm{mN} / \mathrm{m}$ and $22.84 \pm 0.36 \mathrm{mN} / \mathrm{m}$ respectively, and remained almost stable up to $120 \mathrm{~h}$ (Figures 1A,B). Maximum growth was observed at $96 \mathrm{~h}\left(\mathrm{OD}_{660}=2.508\right)$ and didn't increase further till $120 \mathrm{~h}$ (Figure 1C). However no change in $\mathrm{pH}$ was observed until $120 \mathrm{~h}$ (Figure 1D). In corn oil-based production medium maximum reduction in ST and IFT was observed after $96 \mathrm{~h}$, and reached to $30.80 \pm 0.19 \mathrm{mN} / \mathrm{m}$ and $4.26 \pm 0.54 \mathrm{mN} / \mathrm{m}$ from $57.81 \pm 0.79 \mathrm{mN} / \mathrm{m}$ and $25.26 \pm 0.94 \mathrm{mN} / \mathrm{m}$ respectively, and remained almost stable up to $120 \mathrm{~h}$ (Figures 1A,B). Maximum growth was observed at $96 \mathrm{~h}\left(\mathrm{OD}_{660}=2.556\right)$ and decreased thereafter (Figure 1C). The $\mathrm{pH}$ decreased after $72 \mathrm{~h}$ and the medium became acidic (Figure 1D). In production medium containing 'both glucose and corn oil' as carbon sources, maximum reductions in ST and IFT were observed at $48 \mathrm{~h}$ and after $72 \mathrm{~h}$ reached to $28.56 \pm 0.42 \mathrm{mN} / \mathrm{m}$ and $2.13 \pm 0.09 \mathrm{mN} / \mathrm{m}$ from $53.69 \pm 0.36 \mathrm{mN} / \mathrm{m}$ and $23.37 \pm 0.41 \mathrm{mN} / \mathrm{m}$ respectively. The IFT was further reduced to $1.23 \pm 0.02 \mathrm{mN} / \mathrm{m}$ after $96 \mathrm{~h}$ (Figures 1A,B). Maximum growth was observed at $72 \mathrm{~h}\left(\mathrm{OD}_{660}=3.372\right)$ and decreased thereafter (Figure 1C). The $\mathrm{pH}$ remained acidic throughout the experiments (Figure 1D).

In the production media containing both hydrophilic and lipophilic carbon sources (glucose and corn oil), reduction in ST and IFT were observed earlier as compared to production media containing either glucose or corn oil alone. At $48 \mathrm{~h} \mathrm{ST}$ and IFT were reduced to $36.25 \pm 0.43$ and $5.43 \pm 0.36 \mathrm{mN} / \mathrm{m}$, respectively in medium containing 'both glucose and corn oil.' Whereas, in medium containing 'either glucose' or 'only corn oil,' STs and IFTs were reduced to $\sim 46.51 \pm 0.33$ and $\sim 18.66 \pm 0.15 \mathrm{mN} / \mathrm{m}$, respectively. Other researchers also reported that the highest production of SPLs was achieved when glucose was combined with a lipophilic carbon source (Zhou et al., 1992; Davila et al., 1994; Rau et al., 1996; Pekin et al., 2005). SPLs fermentation is a two-step process in which production occurs after growth when nitrogen source has been utilized (Cooper and Paddock, 1984; Davila et al., 1992). SPLs production has been described for cultures with only one carbon source, such as glucose (Hommel et al., 1994) or $n$-alkanes (Davila et al., 1994). However, production was significantly higher when two carbon sources (a carbohydrate based and lipidic one) were simultaneously provided. The various reported carbohydrate based substrates were glucose, sucrose (Klekner et al., 1991), lactose (Zhou and Kosaric, 1993), fructose or mannose (Göbbert et al., 1984). The reported lipidic substrates were $n$-alkanes (Davila et al., 1994), vegetable oils or waste frying oil (Zhou et al., 1992; Shah et al., 2007) or animal fats (Deshpande and Daniels, 1995). Continuous feeding of the lipid substrate, such as fatty acids (Rau et al., 1996) or fatty acid methyl or ethyl esters (Davila et al., 1992), has been shown to improve fermentation performances. The medium should also contain a source of nitrogen such as yeast extracts or corn steep liquor or additional nitrogen sources such as urea or ammonia, citrate buffering compounds and small amount of minerals such as $\mathrm{Mg}^{2+}, \mathrm{Fe}^{3+}, \mathrm{Ca}^{2+}, \mathrm{Zn}^{2+}$, and $\mathrm{Na}^{+}$(Davila et al., 
1992, 1997). We also observed quicker biosurfactant production in medium containing yeast extract and urea with both glucose and corn oil and therefore it was used for further studies.

\section{Stability Studies}

Temperature, $\mathrm{pH}$ and salinity are known to be one of the most important environmental factors influencing the performance of any component (including biosurfactants) to be used for enhanced oil recovery (EOR) purpose. For ex situ microbial enhanced oil recovery (MEOR) applications, biosurfactant must be stable at range of high temperature $\left(\geq 50^{\circ} \mathrm{C}\right)$, effective at wide range of $\mathrm{pH}$ and salt concentration between 7 and $9 \%$ to ensure its applicability to induce oil recovery (Al-Sulaimani et al., 2011b). As shown in Figure 2A, the biosurfactant showed no changes in ST till 10-13\% salt concentration, and at $15-25 \%$ concentration it increased from 31.93 to $40.90 \mathrm{mN} / \mathrm{m}$. Whereas IFT increased to $7.28 \mathrm{mN} / \mathrm{m}$ after adding $1 \%$ salt and thereafter it remained stable till $15 \%$ salt concentration. Which showed clearly that even at high salt concentrations, biosurfactant can perform well and still retain some of its surface activity. As shown in Figure 2B, ST was quite stable at all $\mathrm{pH}$ range with values ranging between 31.0 and $34.0 \mathrm{mN} / \mathrm{m}$. Whereas IFT was stable between $\mathrm{pH}<6$ and $>8$, with corresponding value of $4.31-5.98 \mathrm{mN} / \mathrm{m}$ respectively, and at $\mathrm{pH}$ values between 6 and 8 it showed an increase in IFT value (Figure 2B). Thermal stability profile (Figure 2C) reveals that at different temperatures $\left(40-100^{\circ} \mathrm{C}\right)$ the biosurfactant showed stability at all temperatures tested. These results indicated that the produced biosurfactant is suitable for MEOR applications as it was stable under extreme condition such as salinity, $\mathrm{pH}$ and temperature. This study showed that biosurfactants was quite stable at most salt concentration tested (13-15\%), over a wide range of $\mathrm{pH}$ values tested (2-12), and at different temperatures $\left(40-100^{\circ} \mathrm{C}\right)$. It is comparable with other types of biosurfactants reported by several researchers (Joshi et al., 2008, 2015; Ghojavand et al., 2008; Gudiña et al., 2010; Al-Sulaimani et al., 2011b).

\section{Emulsification Index $\left(\% \mathrm{E}_{24}\right)$}

Emulsification is one of the features of biosurfactant which aids in enhancing the trapped oil from the oil wells. As shown in Figure 3, biosurfactant emulsified a variety of hydrocarbons. It gave high $\% \mathrm{E}_{24}$ with heavy crude oil (68.75\%), and with $n$-hexadecane, light crude oil, $n$-tetradecane, $n$-pentane, $n$-tridecane and 2,2,4,4,6,8-heptamethylnonane also formed stable emulsions, with $\% \mathrm{E}_{24}$ between 34 and $35 \%$. Whereas it showed lower $\% \mathrm{E}_{24}(23.86-29.55 \%)$ against hexane, 1methylnaphthalene and heptane. Higher $\% \mathrm{E}_{24}$ with 'heavy-crude oil' can potentially help in heavy-oil recovery. Al-Wahaibi et al. (2014) reported lipopeptide type of biosurfactant produced by isolate Bacillus subtilis $\mathrm{B} 30$ in minimal medium or molasses medium, which showed around 15-55\% emulsification of various hydrocarbons including light or heavy oils. Ismail and Dadrasnia (2015) also reported $\% \mathrm{E}_{24}$ of novel Bacillus strain 139SI as 69\% with crude oil, thus aiding in bioremediation of oil polluted water. We also observed similar results with biosurfactant produced by C. bombicola.
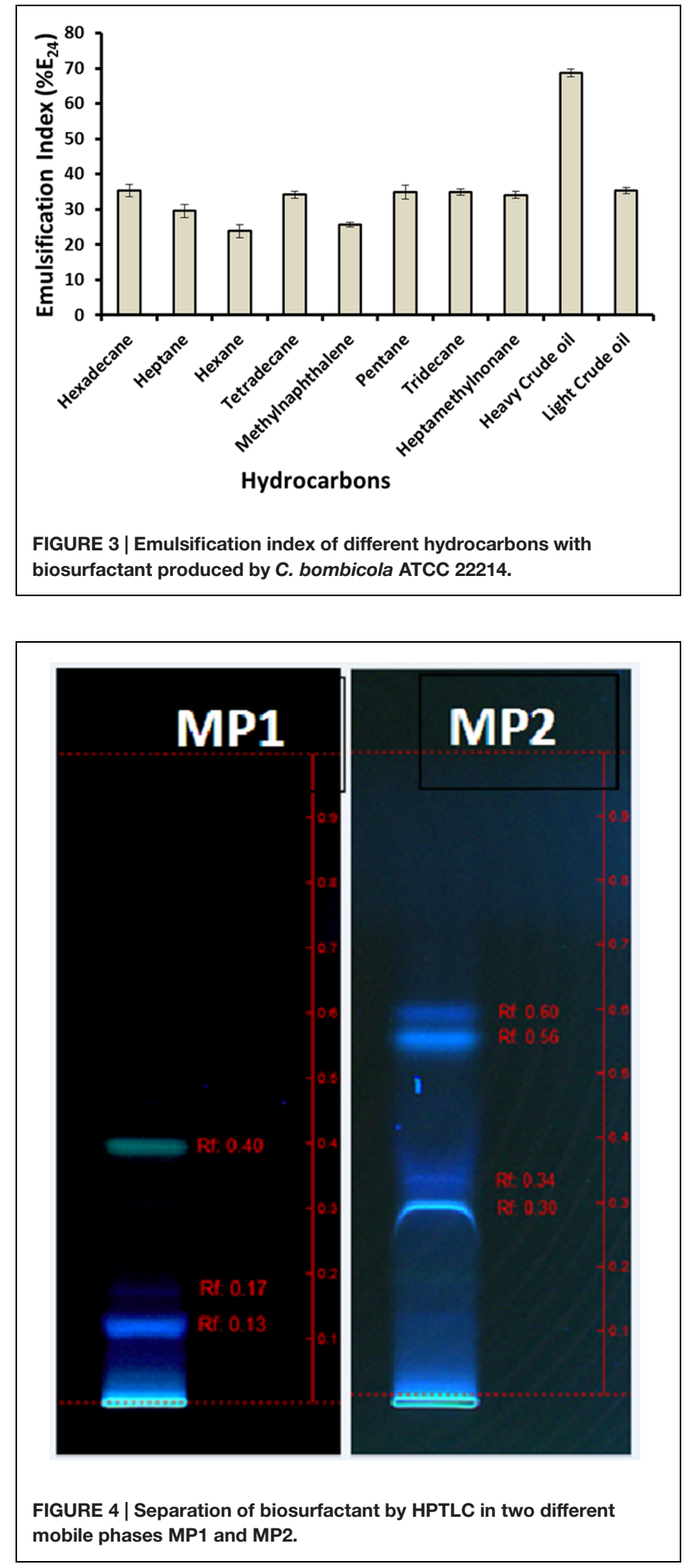

\section{Extraction and Characterization of Biosurfactant}

The biosurfactant was extracted and purified by solvent extraction with ethyl acetate followed by washing with hexane 


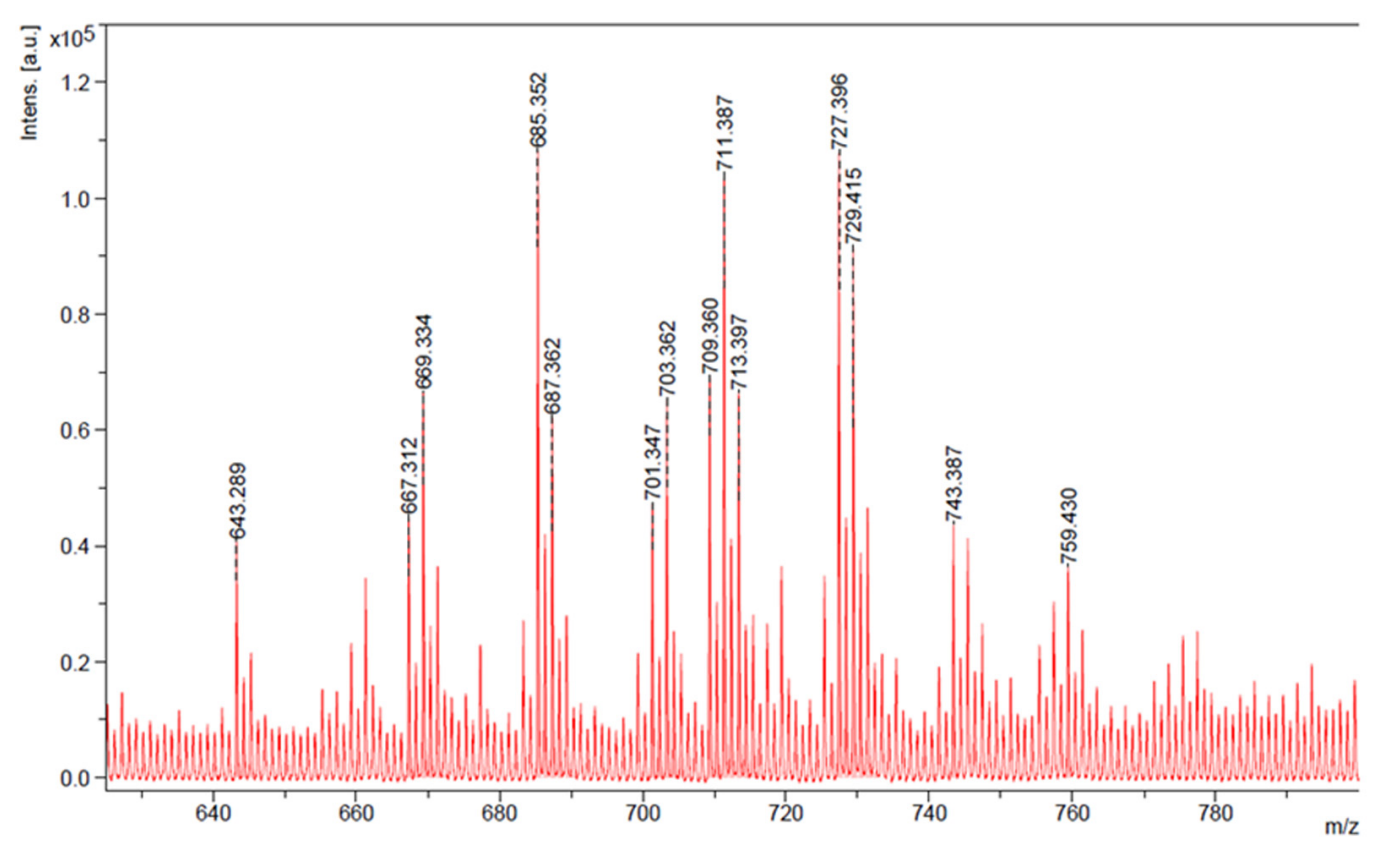

FIGURE 5 | Matrix-assisted laser desorption ionization - time of flight-mass spectroscopy (MALDI-TOF-MS) mass spectrum of produced biosurfactant.

which resulted in $2.42 \mathrm{~g} / \mathrm{l}$ of crude product as yellowish brown powder (Supplementary Figure S1), after evaporation of hexane. In order to confirm the activity of the crude biosurfactant, ST and IFT were analyzed. The ST and IFT were found to be $30.32 \pm 0.31 \mathrm{mN} / \mathrm{m}$ and $2.66 \pm 0.38 \mathrm{mN} / \mathrm{m}$ respectively, which were quite similar to the values of ST and IFT of biosurfactant in broth, before extraction.

The characterization of the surface active components from the crude biosurfactant mixture is important to determine its molecular structure since their structural features may provide very useful information for future research purposes. The biosurfactant obtained using glucose-corn oil based production medium was identified and characterized by different analytical techniques. TLC or HPTLC has been reported as a useful technique for initial qualitative or quantitative analysis of biological active compounds (Al-Wahaibi et al., 2014). Thus we analyzed biosurfactant by HPTLC using two mobile phases, and the separated bands were directly extracted and analyzed for MS detection. Both the MP systems gave good separation of biosurfactant components and the visualization was better under UV 366 nm (Figure 4), and the extracted bands showed mass in the range of 300-795 (Supplementary Figure S2). The MALDITOF further confirmed the mass of the produced SPLs, of which major peaks were in the range of 643-759 Da (Figure 5). It is reported that typical structure of biosurfactant produced by C. bombicola - SPLs consists of a sophorose sugar $\beta$-glycosidically linked to terminal (or subterminally) hydroxylated fatty acid with chain lengths of 16-18, as a mixture of compounds. Where precursor fatty acids added to the production medium leads to formation of different forms of SPLs, which contains both acid and lactone SPLs, but lactones frequently represent the largest fraction of the product (Asmer et al., 1988; Davila et al., 1994; Joshi-Navare et al., 2013). We have used corn oil as a precursor, which is a mixture of fatty acids and thus multiple forms of SPLs with diverse hydrophobic moieties were expected. This was confirmed with the MALDI-TOF-MS analysis of the purified biosurfactant. The major peaks from the mass spectrum were correlated to sodium adducts $\left[\mathrm{M}^{+}+\mathrm{Na}^{+}\right]$of different forms of SPLs, as derived from oleic acid $(m / z 669,687,711,729)$ were detected (Figure 5). Where major ions at $\mathrm{m} / z 711$ and $\mathrm{m} / z 729$ can be attributed to the $\left[\mathrm{M}^{+}+\mathrm{Na}^{+}\right]$adduct ions for the lactone and free acid forms of the major diacetylated SPLs respectively (Asmer et al., 1988; Kurtzman et al., 2010). Other ions at $\mathrm{m} / \mathrm{z}$ 669 and $m / z 687$ correspond to the monoacetylated forms of the major SPLs, whereas the non-acetylated forms were not observed in current biosurfactant. The observed difference between these two sets of ions (729-711 and 687-669) can be attributed to the mass difference between the free acid form and the ester-linked lactone form of SPLs respectively. Thus the mass of produced SPLs can be calculated as from $\sim 646$ to 706 . Kurtzman et al. (2010) reported production and characterization of SPLs by multiple species of the Starmerella (Candida) bombicola yeast clade, using high-throughput MALDI-TOF-MS analysis. They reported SPLs production using oleic acid as fatty acid precursor along with other components in the production medium, and thus observed only oleic acid containing SPLs. Whereas we have used corn oil as fatty acid precursor and observed other minor SPLs derived from other types of acids present in corn oil, as sodium adducts $\left[\mathrm{M}^{+}+\mathrm{Na}^{+}\right]$derived from palmitic $(m / z 685$, $703)$, linoleic $(m / z 709,727)$, and trace amounts of stearic $(m / z$ $713)$ and arachidic $(\mathrm{m} / z$ 759) acid (Figure 5$)$. The mass difference $(18 \mathrm{Da})$ between the two sets of ions derived from palmitic and 


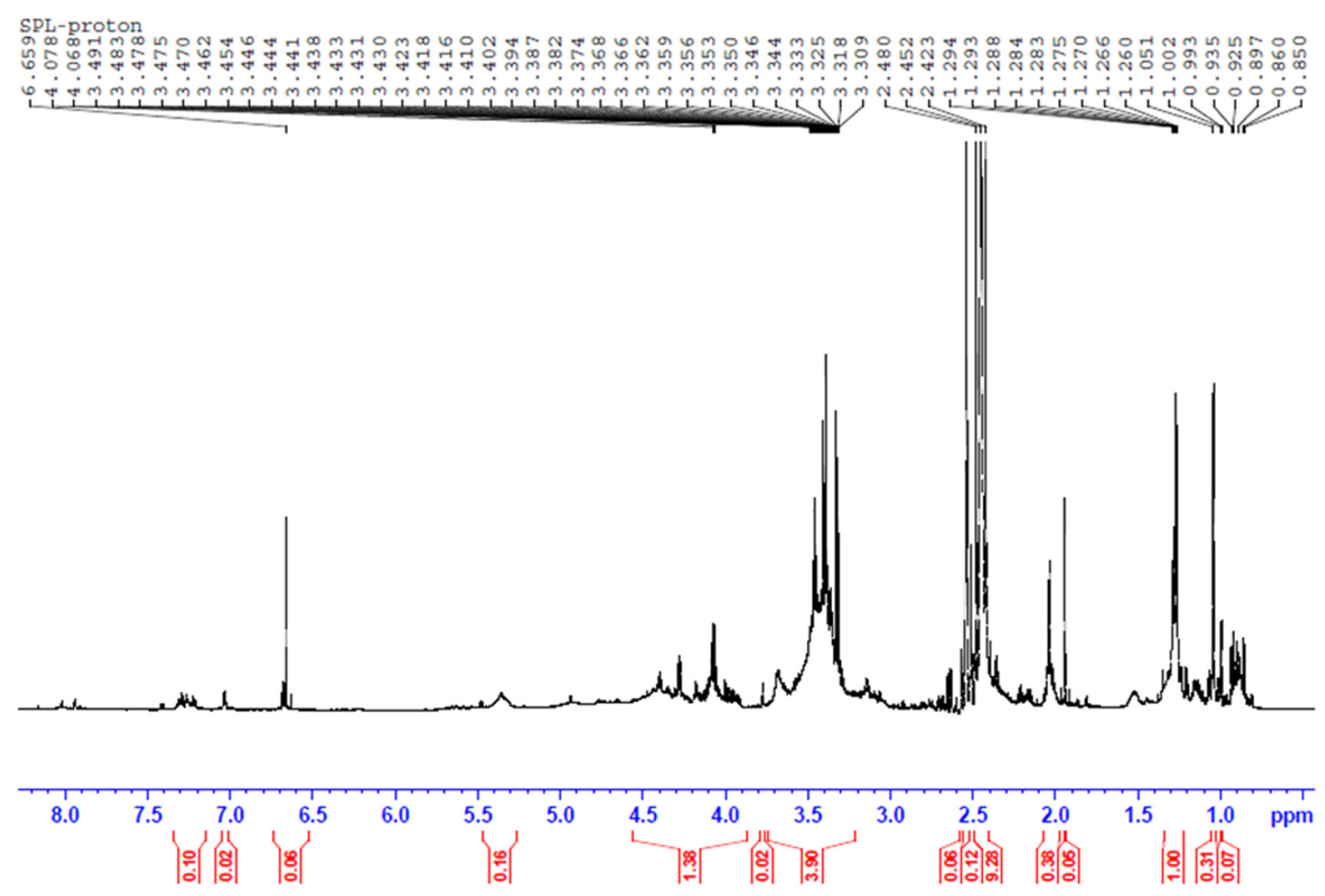

FIGURE 6 | The proton $\left({ }^{1} \mathrm{H}\right)$ NMR spectrum of produced biosurfactant.

linoleic acids are again indicative of the free acid and lactone forms of the minor SPLs respectively. Similar type of SPLs ions were identified and reported previously from C. bombicola and other yeast species using fast atom bombardment MS or MALDITOF MS (Asmer et al., 1988; Kurtzman et al., 2010; Joshi-Navare et al., 2013).

The structures of biosurfactants were further confirmed by ${ }^{1} \mathrm{H}$, and proton decoupled ${ }^{13} \mathrm{C}-\mathrm{NMR}$ and the results are shown in Figures 6 and 7 . The ${ }^{1} \mathrm{H}$ NMR spectrum of the purified biosurfactant in $\mathrm{CDCl}_{3}$ was assigned to a typical glycolipidtype structure and characteristic proton chemical shift peaks could be observed (Figure 6). Multiple signals of protons of $\left(-\mathrm{CH}_{3}\right)$ below $1.0 \mathrm{ppm}$ and of $\left(-\mathrm{CH}_{2}\right)$ between 1.0 and $1.4 \mathrm{ppm}$ revealed the existence of a linear alkane, and signals at 5.3$5.4 \mathrm{ppm}$ revealed presence of $(-\mathrm{CH}=\mathrm{CH}-)$ group in the fatty acid chain. The signal at $5.3-5.4 \mathrm{ppm}$ is attributable to an unsaturated hydrocarbon moiety, also consistent with the oleic acid derived SPLs signatures in MALDI-TOF-MS analysis. Protons of $\left(-\mathrm{CH}_{2}\right)$ bonded to carboxylic group of fatty acid resonated at $\sim 1.99 \mathrm{ppm}$, and $\sim 2.09 \mathrm{ppm}$ revealed the presence of $\left(-\mathrm{COCH}_{3}\right)$ group in biosurfactant. Resonance of protons belonging to sophorose moiety resulted in peaks within the region 4-4.5 ppm, and the other protons of sugar were resonated at $3.18-3.8$ ppm.

The ${ }^{13} \mathrm{C}$ NMR spectrum of the biosurfactant showed the presence of two $(=\mathrm{CH}-)$ groups in the fatty acid chain moiety corresponding to signals at $130.41 \mathrm{ppm}$ and $128.99 \mathrm{ppm}$; and few more $(=\mathrm{CH}-)$ groups in the fatty chain moiety were resonated between 128 and $130 \mathrm{ppm}$, which may be probably due to contribution from other interfering group of biosurfactant in the sample (Figure 7$)$. In addition, several $\left(-\mathrm{CH}_{2}-\right)$ groups in the fatty chain moiety were also resonated at 20 35 ppm. The spectrum also revealed signals of glucose- C- $1^{\prime \prime}$ at $101.24 \mathrm{ppm}$, glucose-C-6', and glucose-C-6" at 64.08, $62.29 \mathrm{ppm}$; the other carbon atoms of glucose were resonated between $70 \sim 78 \mathrm{ppm}$. The peaks derived from the carbonyl groups $(-\mathrm{CO}-)$ were shown at $170 \sim 177 \mathrm{ppm}$. The chemicals shifts were comparable to previous reports (Daverey and Pakshirajan, 2009, 2010; Wadekar et al., 2012; Joshi-Navare et al., 2013). The MALDI-TOF-MS and NMR results further confirmed the biosurfactant as a mixture of SPLs with mono and diacetylated SL as mixture of different fatty acids in acidic or lactonic form.

\section{Core-flood Experiments}

An area of considerable potential for biosurfactant application is in the field of MEOR. Since oil is a critical energy source that drives industrialization and sustained economic development of the world (Youssef et al., 2006). McInerney et al. (2005) documented that current oil production technologies recover only about one-third to one-half of the oil originally present in an oil reservoir. So, EOR methods were developed to recover oil remaining in reservoirs after primary and secondary recovery procedures. MEOR is an important tertiary recovery technology which utilizes microorganisms and/or their metabolites for residual oil recovery (Banat, 1995) which was attempted more than 60 years ago (Hitzman, 1991). We checked the potential of 


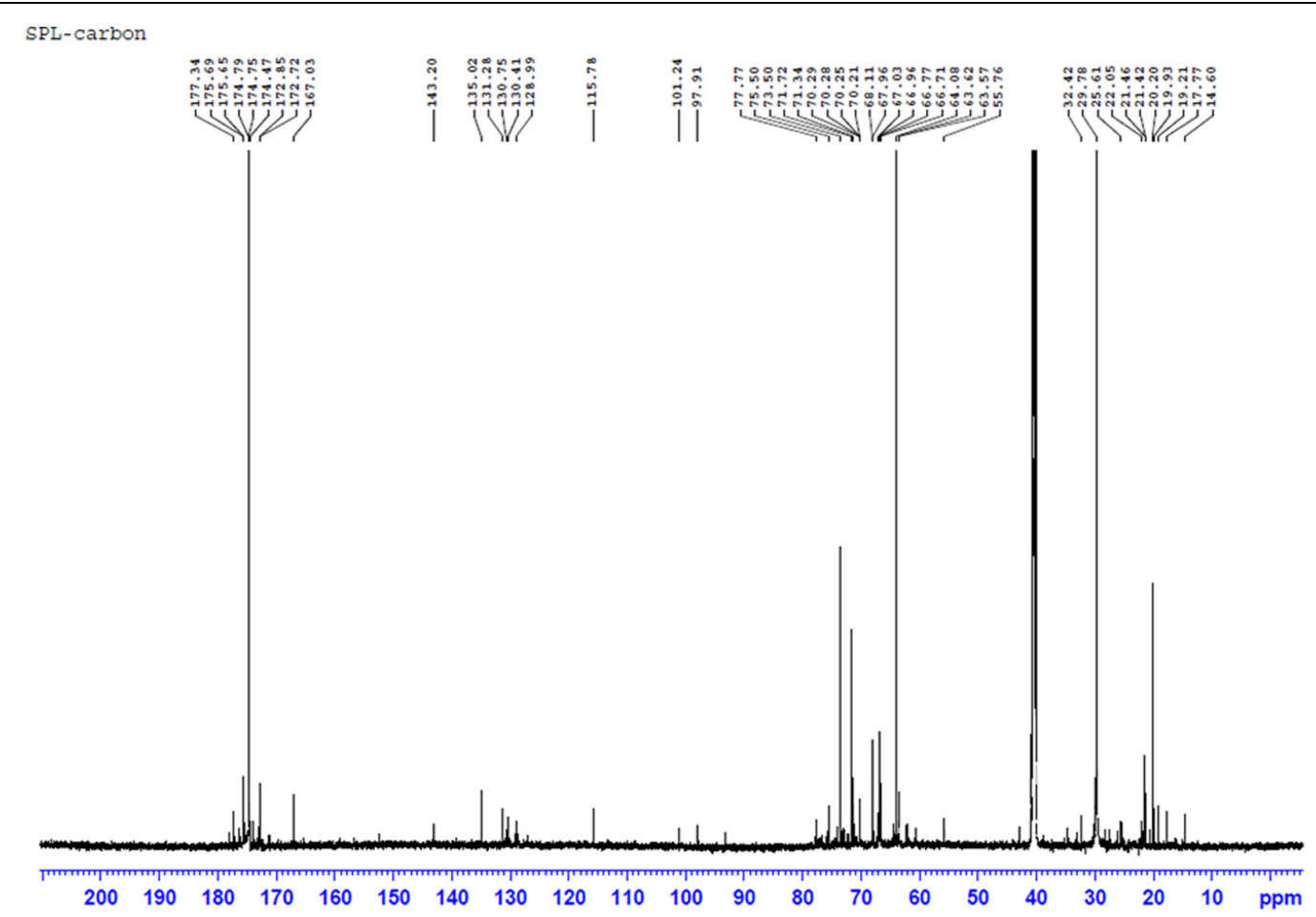

FIGURE 7 | The proton decoupled-carbon $\left({ }^{13} \mathrm{C}\right)$ NMR spectrum of produced biosurfactant.

produced SPLs in MEOR using core-flooding experiments. The $\mathrm{PV}$ of the core-sample was $18 \mathrm{~cm}^{3}$. Initial oil saturation $\left(\mathrm{So}_{\mathrm{i}}\right)$ was calculated to be $55-60 \%$ after oil flooding. It was found that after injecting 5-8 PV of formation water, no more oil was produced and residual oil saturation $\left(\mathrm{So}_{\mathrm{r}}\right.$ ) was about $20 \%$. Extra oil recovery was observed after injecting 4-5 PV SPLs, where $27.27 \%$ of Sor was produced (Figure 8). An increase in oil recovery in ex situ MEOR experiments was detected following SPLs injection. This is similar to reports shown by other researchers for different types of biosurfactants (Al-Sulaimani et al., 2011b; Castorena-Cortés et al., 2012; Joshi et al., 2015). No study was reported before to test the ability of SPLs in enhancing oil recovery using core flood experiments. To the best of our knowledge, this study was the first to explore the efficiency of SPLs to recover oil and it can be used in biosurfactant based MEOR applications. There are various experiment at laboratory scale that have been used to prove the effectiveness of using biosurfactants for microbial enhancing oil recovery, such experiments include sand-pack columns or coreflooding and field trials (Yakimov et al., 1997; Youssef et al., 2006; Joshi and Desai, 2013; Al-Wahaibi et al., 2014). This research is the first report to investigate the ability of SPLs produced by C. bombicola ATCC22214 to enhance oil recovery using core-flooding. Biosurfactants like SPLs are considered as green alternatives for chemical counterparts, as it can be produced from renewable sustainable resources. Production economy is still considered as bottleneck for widespread biosurfactants applications, which hinders the field-scale applications. The cost of production can be drastically reduced when agro-industrial waste products (like molasses) or used waste frying oil (as fatty

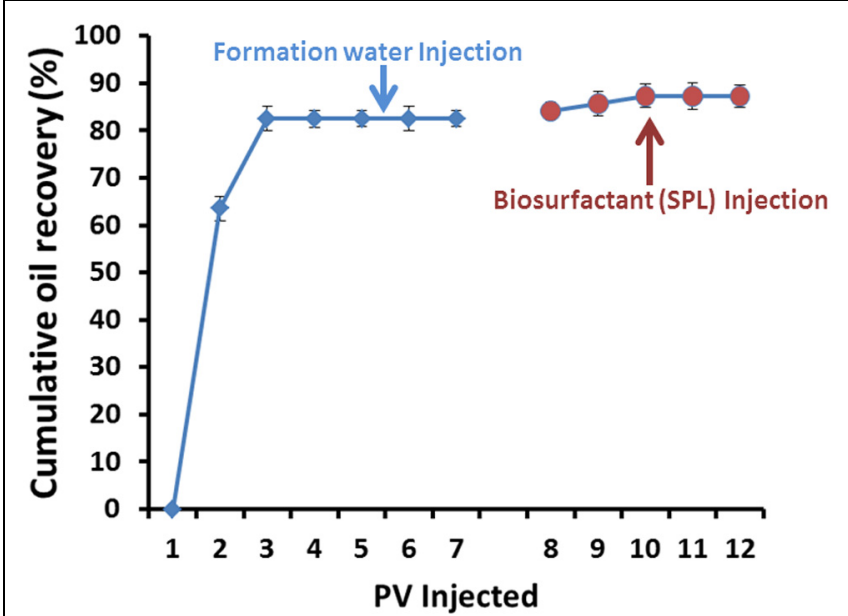

FIGURE 8 | Cumulative oil recovery as a function of pore volumes (PV) injected of formation water and biosurfactant-SPLs.

acid supplement) be used as raw material for SPLs production at large scale fermentation (Makkar et al., 2011; Banat et al., 2014). Once scaled-up, these SPLs can be used for biosurfactant based MEOR or environmental bioremediation, without much purification so that the cost of application can be further reduced. Thus large scale production of SPLs using cheaper raw materials and field-scale MEOR application are further proposed. 


\section{CONCLUSION}

This study shows that corn oil could be used as a carbon source along with glucose to produce SPLs by the yeast C. bombicola ATCC22214. The SPLs showed reduction of ST and IFT; high $\% \mathrm{E}_{24}$ against various hydrocarbons including light and heavy crude oils, and also showed high stability under extreme conditions of salinity, $\mathrm{pH}$ and temperature. It was characterized as a mixture of SPLs, using different analytical techniques. To the best of our knowledge this is the first report on using SPLs for testing MEOR applications. Core-flooding studies revealed that it can recover $27.27 \%$ of residual oil $\left(\mathrm{S}_{\mathrm{or}}\right)$ trapped between the pores of Berea sandstone cores, which highlight the potential applications of SPLs in MEOR.

\section{REFERENCES}

Al-Bahry, S. N., Al-Wahaibi, Y. M., Elshafie, A. E., Al-Bemani, A. S., Joshi, S. J., Al-Makhmari, H. S., et al. (2013). Biosurfactant production by Bacillus subtilis B20 using date molasses and its possible application in enhanced oil recovery. Int. Biodeterior. Biodegradation 81, 141-146. doi: 10.1016/j.ibiod.2012.0 1.006

Al-Sulaimani, H., Joshi, S., Al-Wahaibi, Y., Al-Bahry, S., Elshafie, A., and AlBemani, A. (2011a). Microbial biotechnology for enhancing oil recovery: current developments and future prospects. Biotechnol. Bioinform. Bioeng. 1, 147-158.

Al-Sulaimani, H., Al-Wahaibi, Y., Al-Bahry, S., Elshafie, A., Al-Bemani, A., Joshi, S., et al. (2011b). Optimization and partial characterization of biosurfactants produced by Bacillus species and their potential for ex-situ enhanced oil recovery. SPE J. 16, 672-682. doi: 10.2118/129228-pa

Al-Wahaibi, Y., Joshi, S., Al-Bahry, S., Elshafie, A., Al-Bemani, A., and Shibulal, B. (2014). Biosurfactant production by Bacillus subtilis B30 and its application in enhancing oil recovery. Colloids Surf. B Biointerfaces 114, 324-333. doi: 10.1016/j.colsurfb.2013.09.022

Asmer, H. J., Lang, S., Wagner, F., and Wray, V. (1988). Microbial production, structure elucidation and bioconversion of sophorose lipids. J. Am. Oil Chemists' Society 65, 1460-1466. doi: 10.1007/bf02898308

Banat, I. M. (1995). Biosurfactants production and possible uses in microbial enhanced oil recovery and oil pollution remediation: a review. Bioresour. Technol. 51, 1-12. doi: 10.1016/0960-8524(94)00101-6

Banat, I. M., Samarah, N., Murad, M., Horne, R., and Banerjee, S. (1991). Biosurfactant production and use in oil tank clean-up. World J. Microbiol. Biotechnol. 7, 80-88. doi: 10.1007/bf02310921

Banat, I. M., Satpute, S. K., Cameotra, S. S., Patil, R., and Nyayanit, N. V. (2014). Cost effective technologies and renewable substrates for biosurfactants' production. Front. Microbiol. 5:697. doi: 10.3389/fmicb.2014.00697

Castorena-Cortés, G., Roldán-Carrillo, T., Reyes-Avila, J., Zapata-Peñasco, I., Mayol-Castillo, M., and Olguín-Lora, P. (2012). Coreflood assay using extremophile microorganisms for recovery of heavy oil in Mexican oil fields. J. Biosci. Bioeng. 114, 440-445. doi: 10.1016/j.jbiosc.2012.0 5.011

Cooper, D. G., and Paddock, D. A. (1984). Production of a biosurfactant from Torulopsis bombicola. Appl. Environ. Microbiol. 47, 173-176.

Daverey, A., and Pakshirajan, K. (2009). Production of sophorolipids by the yeast Candida bombicola using simple and low cost fermentative media. Food Res. Int. 42, 499-504. doi: 10.1016/j.foodres.2009.01.014

Daverey, A., and Pakshirajan, K. (2010). Sophorolipids from Candida bombicola using mixed hydrophilic substrates: production, purification and characterization. Colloids Surf. B Biointerfaces 79, 246-253. doi: 10.1016/j.colsurfb.2010.04.002

Davila, A.-M., Marchal, R., and Vandecasteele, J.-P. (1994). Sophorose lipid production from lipidic precursors: predictive evaluation of industrial substrates. J. Ind. Microbiol. 13, 249-257. doi: 10.1007/bf01569757

\section{ACKNOWLEDGMENTS}

This research was financially supported by Petroleum Development Oman, Oman (CR/SCI/BIOL/11/01). Authors kindly acknowledge Ms. Asma Al-Bahri for HPTLC analysis and Dr. Premkumar Samuel for MALDI-TOF and NMR analysis, Central Analytical and Applied Research Unit, Sultan Qaboos University, Oman.

\section{SUPPLEMENTARY MATERIAL}

The Supplementary Material for this article can be found online at: http://journal.frontiersin.org/article/10.3389/fmicb. 2015.01324

Davila, A. M., Marchal, R., and Vandecasteele, J. P. (1997). Sophorose lipid fermentation with differentiated substrate supply for growth and production phases. Appl. Microbiol. Biotechnol. 47, 496-501. doi: 10.1007/s002530050962

Davila, A.-M., Marchal, R. M., and Vandecasteele, J.-P. (1992). Kinetics and balance of a fermentation free from product inhibition: sophorose lipid production by Candida bombicola. Appl. Microbiol. Biotechnol. 38, 6-11. doi: $10.1007 /$ bf00169410

Desai, J. D., and Banat, I. M. (1997). Microbial production of surfactants and their commercial potential. Microbiol. Mol. Biol. Rev. 61, 47-64.

Deshpande, M., and Daniels, L. (1995). Evaluation of sophorolipid biosurfactant production by Candida bombicola using animal fat. Bioresour. Technol. 54, 143-150. doi: 10.1016/0960-8524(95)00116-6

Ghojavand, H., Vahabzadeh, F., Roayaei, E., and Shahraki, A. K. (2008). Production and properties of a biosurfactant obtained from a member of the Bacillus subtilis group (PTCC 1696). J. Colloid Interface Sci. 324, 172-176. doi: 10.1016/j.jcis.2008.05.001

Göbbert, U., Lang, S., and Wagner, F. (1984). Sophorose lipid formation by resting cells of Torulopsis bombicola. Biotechnol. Lett. 6, 225-230. doi: 10.1007/bf00140041

Gudiña, E. J., Teixeira, J. A., and Rodrigues, L. R. (2010). Isolation and functional characterization of a biosurfactant produced by Lactobacillus paracasei. Colloids Surf. B Biointerfaces 76, 298-304. doi: 10.1016/j.colsurfb.2009.11.008

Hitzman, D. O. (1991). Ch. I-2 microbial enhanced oil recovery-the time is now. Dev. Pet. Sci. 31, 11-20. doi: 10.1016/s0376-7361(09)70145-1

Hommel, R. K., Weber, L., Weiss, A., Himmelreich, U., Rilke, O., and Kleber, H. P. (1994). Production of sophorose lipid by Candida (Torulopsis) apicola grown on glucose. J. Biotechnol. 33, 147-155. doi: 10.1016/0168-1656(94)90107-4

Ismail, S., and Dadrasnia, A. (2015). Biotechnological potential of Bacillus salmalaya 139SI: a novel strain for remediating water polluted with crude oil waste. PLoS ONE 10:e0120931. doi: 10.1371/journal.pone.0120931

Joshi, S., Bharucha, C., Jha, S., Yadav, S., Nerurkar, A., and Desai, A. J. (2008). Biosurfactant production using molasses and whey under thermophilic conditions. Bioresour. Technol. 99, 195-199. doi: 10.1016/j.biortech.2006.12.010

Joshi, S. J., and Desai, A. J. (2010). "Biosurfactant's role in bioremediation of NAPL and fermentative production," in Biosurfactants, ed. R. Sen (New York, NY: Springer), 222-235. doi: 10.1007/978-1-4419-5979-9_17

Joshi, S. J., and Desai, A. J. (2013). Bench-scale production of biosurfactants and their potential in ex-situ MEOR application. Soil Sediment Contam. 22, 701-715. doi: 10.1080/15320383.2013.756450

Joshi, S. J., Geetha, S. J., and Desai, A. J. (2015). Characterization and application of biosurfactant produced by Bacillus licheniformis R2. Appl. Biochem. Biotechnol. 177, 346-361. doi: 10.1007/s12010-015-1746-4

Joshi-Navare, K., Khanvilkar, P., and Prabhune, A. (2013). Jatropha oil derived sophorolipids: production and characterization as laundry detergent additive. Biochem. Res. Int. 2013, 1-11. doi: 10.1155/2013/169797

Kachholz, T., and Schlingmann, M. (1987). "Possible food and agriculture application of microbial surfactants: an assessment," in Biosurfactants and Biotechnology, ed. N. Kosaric (New York, NY: Dekker), 183-210. 
Klekner, V., Kosaric, N., and Zhou, Q. H. (1991). Sophorose lipids produced from sucrose. Biotechnol. Lett. 13, 345-348. doi: 10.1007/bf01027680

Kurtzman, C. P., Price, N. P. J., Ray, K. J., and Kuo, T.-M. (2010). Production of sophorolipid biosurfactants by multiple species of the Starmerella (Candida) bombicola yeast clade. FEMS Microbiol. Lett. 311, 140-146. doi: 10.1111/j.15746968.2010.02082.x

Levison, M. I. (2009). "Surfactant production, present realities and future perspectives," in Handbook of Detergents Part F: Production, Vol. 142, eds U. Zoller and P. Sois (Boca Raton: CRC Press), 1-38.

Makkar, R. S., Cameotra, S. S., and Banat, I. M. (2011). Advances in utilization of renewable substrates for biosurfactant production. Appl. Microbiol. Biotechnol. Express 1, 1-5. doi: 10.1186/2191-0855-1-5

Mann, R. M., and Bidwell, J. R. (2001). The acute toxicity of agricultural surfactants to the tadpoles of four Australian and two exotic frogs. Environ. Pollut. 114, 195-205. doi: 10.1016/s0269-7491(00)00216-5

Mann, R. M., and Boddy, M. R. (2000). Biodegradation of a nonylphenol ethoxylate by the autochthonous microflora in lake water with observations on the influence of light. Chemosphere 41, 1361-1369. doi: 10.1016/s00456535(00)00002-3

Marchant, R., and Banat, I. M. (2012a). Biosurfactants: a sustainable replacement for chemical surfactants? Biotechnol. Lett. 34, 1597-1605. doi: 10.1007/s10529012-0956-x

Marchant, R., and Banat, I. M. (2012b). Microbial biosurfactants: challenges and opportunities for future exploitation. Trends Biotechnol. 30, 558-565. doi: 10.1016/j.tibtech.2012.07.003

McInerney, M. J., Nagle, D. P., and Knapp, R. M. (2005). “Microbially enhanced oil recovery: past, present and future," in Petroleum Microbiology, eds B. Ollivier and M. Magot (Washington, DC: ASM Press), 215-237.

Pekin, G., Vardar-Sukan, F., and Kosaric, N. (2005). Production of sophorolipids from Candida bombicola ATCC 22214 using turkish corn oil and honey. Eng. Life Sci. 5, 357-362. doi: 10.1002/elsc.200520086

Rau, U., Manzke, C., and Wagner, F. (1996). Influence of substrate supply on the production of sophorose lipids by Candida bombicola ATCC 22214. Biotechnol. Lett. 18, 149-154. doi: 10.1007/bf00128670

Sen, R. (2008). Biotechnology in petroleum recovery: the microbial EOR. Prog. Energy Combust. Sci. 34, 714-724. doi: 10.1016/j.pecs.2008.05.001

Shah, V., Doncel, G. F., Seyoum, T., Eaton, K. M., Zalenskaya, I., Hagver, R., et al. (2005). Sophorolipids, microbial glycolipids with anti-human immunodeficiency virus and sperm-immobilizing activities. Antimicrob. Agents Chemother. 49, 4093-4100. doi: 10.1128/aac.49.10.4093-4100.2005
Shah, V., Jurjevic, M., and Badia, D. (2007). Utilization of restaurant waste oil as a precursor for sophorolipid production. Biotechnol. Prog. 23, 512-515. doi: 10.1021/bp0602909

Van Bogaert, I. N. A., Saerens, K., De Muynck, C., Develter, D., Soetaert, W., and Vandamme, E. J. (2007). Microbial production and application of sophorolipids. Appl. Microbiol. Biotechnol. 76, 23-34. doi: 10.1007/s00253-0070988-7

Van Bogaert, I. N. A., Zhang, J., and Soetaert, W. (2011). Microbial synthesis of sophorolipids. Process. Biochem. 46, 821-833. doi: 10.1016/j.procbio.2011.01.010

Wadekar, S. D., Kale, S. B., Lali, A. M., Bhowmick, D. N., and Pratap, A. P. (2012). Utilization of sweetwater as a cost-effective carbon source for sophorolipids production by Starmerella bombicola (ATCC 22214). Prep. Biochem. Biotechnol. 42, 125-142. doi: 10.1080/10826068.2011.577883

Yakimov, M. M., Amro, M. M., Bock, M., Boseker, K., Fredrickson, H. L., Kessel, D. G., et al. (1997). The potential of Bacillus licheniformis strains for in situ enhanced oil recovery. J. Pet. Sci. Eng. 18, 147-160. doi: 10.1016/s09204105(97)00015-6

Youssef, N., Simpson, D. R., Duncan, K. E., Mcinerney, M. J., Folmsbee, M., Fincher, T., et al. (2006). In situ biosurfactant production by Bacillus strains injected into a limestone petroleum reservoir. Appl. Environ. Microbiol. 73, 1239-1247. doi: 10.1128/aem.02264-06

Zhou, Q. H., Klekner, V., and Kosaric, N. (1992). Production of sophorose lipids by Torulopsis bombicola from safflower oil and glucose. J. Am. Oil Chem. Soc. 69, 89-91. doi: 10.1007/bf02635883

Zhou, Q. H., and Kosaric, N. (1993). Effect of lactose and olive oil on intra- and extracellular lipids of Torulopsis bombicola. Biotechnol. Lett. 15, 477-482. doi: 10.1007/bf00129322

Conflict of Interest Statement: The authors declare that the research was conducted in the absence of any commercial or financial relationships that could be construed as a potential conflict of interest.

Copyright $\odot 2015$ Elshafie, Joshi, Al-Wahaibi, Al-Bemani, Al-Bahry, Al-Maqbali and Banat. This is an open-access article distributed under the terms of the Creative Commons Attribution License (CC BY). The use, distribution or reproduction in other forums is permitted, provided the original author(s) or licensor are credited and that the original publication in this journal is cited, in accordance with accepted academic practice. No use, distribution or reproduction is permitted which does not comply with these terms. 